\title{
EL DEBER DE NO COMPETENCIA DESLEAL DEL TRABAJADOR EN ESPAÑA
}

\section{THE DUTY OF UNFAIR COMPETITION OF THE EMPLOYEE IN SPAIN}

\section{O DEVE DA NÃO COMPETENCIA DESLEAL DO TRABALHADOR NA ESPANHA}

\author{
JORDI GARCÍA VIÑA
}

Catedrático de Derecho del Trabajo y de la Seguridad Social. Universidad de Barcelona. España. E-mail: jordi.garcia@ub.edu

\section{RESUMEN}

El respeto a la competencia entre empresas es uno de los elementos esenciales del sistema de libre mercado. Por esta razón, el Ordenamiento Jurídico tiene mucho interés en regular medidas que eliminen cualquier conducta que suponga una intromisión. Este es el objetivo de la prohibición de competencia desleal que el Estatuto de los Trabajadores regula como deber de los trabajadores en España. Summary: Respect for competition between companies is one of the essential elements of the free market system. For this reason, the Legal Order is very interested in regulating measures that eliminate any conduct that implies any interference. This is the objective of the prohibition of unfair competition that the Workers' Statute regulates as duty of employees in Spain.

PALABRAS CLAVE: Buena Fe; Trabajador; Competencia Desleal. 


\begin{abstract}
Respect for competition between companies is one of the essential elements of the free market system. For this reason, the Legal Order is very interested in regulating measures that eliminate any conduct that implies an interference. This is the objective of the prohibition of unfair competition that the Workers' Statute regulates as a duty of workers in Spain. Summary: Respect for competition between companies is one of the essential elements of the free market system. For this reason, the Legal Order is very interested in regulating measures that eliminate any conduct that implies any interference. This is the objective of the prohibition of unfair competition that the Workers' Statute regulates the duty of employees in Spain.
\end{abstract}

KEYWORDS: Good Faith; Employee; Unfair Competition.

\title{
RESUMO
}

O respeito pela concorrência entre empresas é um dos elementos essenciais do sistema de mercado livre. Por essa razão, o Departamento Jurídico está muito interessado em regulamentar medidas que eliminem qualquer conduta que implique uma interferência. Este é o objetivo da proibição da concorrência desleal que o Estatuto dos Trabalhadores regula como um dever dos trabalhadores na Espanha. Resumo: $O$ respeito pela concorrência entre empresas é um dos elementos essenciais do sistema de mercado livre. Por esta razão, o Decreto está muito interessado em regulamentar medidas que eliminem qualquer conduta que implique qualquer interferência. Este é o objetivo da proibição da concorrência desleal de que o Estatuto dos Trabalhadores regule o dever dos empregados na Espanha.

PALAVRAS-CHAVE: Boa Fé, Empregado, Concorrência Desleal.

\section{INTRODUCCIÓN}


Las conductas del trabajador que pueden incluirse en el concepto de competencia desleal son cada día más relevantes, ya que el perjuicio pasa a primer plano. Todo ello, teniendo muy en cuenta que los sistemas de economía de mercado, como los que existen en la mayoría de países, se asientan sobre determinados principios de muy variada instrumentación jurídico-legal, entre los que cabe citar la libertad de industria y de comercio, la libertad de acceso al mercado, la libertad de iniciativa económica, la libre competencia, la autonomía privada y la libertad contractual.

Lógica consecuencia del principio de libre competencia, inherente al sistema de economía de mercado, es la ausencia, o mejor la inexistencia, de un derecho del empresario a su clientela, en cuanto que si se consagrara un derecho empresarial a la propia clientela equivaldría a negar el principio de la libre concurrencia.

No obstante, el adecuado funcionamiento del sistema capitalista, y la incorporación del elemento social a la economía de mercado, imponen la adopción de determinadas restricciones y limitaciones de la competencia, que encuentran su justificación en el interés general. Es lo que se conoce como "Derecho de la Competencia", integrado por el conjunto de reglas de Derecho a las que se han de someter las actividades competitivas de los empresarios en la búsqueda y mantenimiento de su clientela.

Esta materia, aunque en su faceta colectiva, especialmente relacionada con la negociación colectiva, está adquiriendo en los últimos tiempos gran importancia, ya que tanto los tribunales de la Unión Europea, como los españoles, así como el organismo competente en España sobre este tema, la Comisión Nacional de los Mercados y de la Competencia, están afirmando que este derecho a la competencia de los empresarios no puede verse alterado por la regulación contenida en un convenio colectivo.

Los empresarios preservan su clientela de un modo indirecto, al reconocérseles un derecho a proteger los llamados factores de clientela o elementos que coordinados producen la clientela, tales como locales comerciales, nombre comercial, marcas y signos distintivos en general, personal colaborador, auxiliares, 
vendedores, etc; es decir, todos aquellos elementos que, convenientemente dispuestos y distribuidos, constituyen la verdadera organización empresarial.

Esta protección se lleva a cabo en España con normas de muy variado contenido, entre las que cabe destacar regulaciones de carácter mercantil, penal e incluso laboral. Entre las normas mercantiles, además de la Ley 3/1991, de 10 de enero, de competencia desleal, verdadera clave del sistema, se puede citar el Código de comercio, concretamente en sus artículos 136 y 137 para los socios de las sociedades colectivas, 288 respecto a los factores mercantiles o 613 para capitán de buque. Existen además limitaciones en cuanto a esta materia para los administradores de las sociedades capitalistas, el Real Decreto Legislativo 1/2010, de 2 de julio, por el que se aprueba el texto refundido de la Ley de Sociedades de Capital, se refiere en el art. 227 a su deber de lealtad y en el art. 229.1.f a la obligación de evitar situaciones de conflicto de interés en relación a "Desarrollar actividades por cuenta propia o cuenta ajena que entrañen una competencia efectiva, sea actual o potencial, con la sociedad o que, de cualquier otro modo, le sitúen en un conflicto permanente con los intereses de la sociedad".

Finalmente, en el ámbito penal, los artículos 278 a 286 del Código Penal, dedicados a los delitos relativos al mercado y a los consumidores, tratan aspectos que claramente se relacionan con la eliminación de la libre competencia del mercado.

Asimismo, y con la finalidad de evitar la competencia, presente o futura, de los trabajadores al servicio del empresario, que es uno de los medios reconocidos como lícitos por el Ordenamiento Jurídico para proteger la clientela empresarial, los artículos 5.d), 21 y 54.2.d) del Estatuto de los Trabajadores (en adelante, ET), se dirigen a esta finalidad.

En todos los ámbitos, y en material laboral especialmente, la competencia puede prohibirse o limitarse atendiendo básicamente a dos razones: el interés público o el interés privado.

Dejando aparte el interés público, por no ser objeto de estudio en este trabajo, las restricciones a la competencia a causa del interés privado pueden provenir de una ley o nacer de un acuerdo entre las partes, denominado contrato.

En primer lugar, la Ley fija límites al ejercicio de la actividad a cargo de determinados sujetos en función de la naturaleza peculiar de determinadas relaciones 
a favor de los particulares. Se produce con ello una excepcional, y a la vez limitada constitución de derechos subjetivos privados, que permiten exigir a determinados sujetos la abstención de determinadas actividades. Esta función se ha denominado tradicionalmente limitación de los derechos subjetivos.

Así, en el Ordenamiento Español existen prohibiciones legales de competir que afectan a los factores mercantiles, capitanes de barco, sobrecargos, administradores de sociedades, socios colectivos, socios industriales, y finalmente, en lo que afecta directamente a este trabajo, trabajadores por cuenta ajena.

En segundo lugar, cuando las prohibiciones o limitaciones proceden de un contrato, como manifestación del principio de libertad contractual y de autonomía privada, la ley interviene sólo para fijar límites que garanticen el equilibrio de prestaciones entre las partes.

Por supuesto, intentar armonizar los intereses de empresarios y trabajadores en este tema no es tarea fácil. La legislación laboral, de claro sentido tutelar y protector, parte de considerar desiguales a los sujetos del contrato de trabajo, ya desde el mismo momento de su celebración. Por esta razón, trata de impedir que los trabajadores, parte débil de esta relación, puedan verse compelidos a aceptar cláusulas de prohibición de competencia que les resulten extraordinariamente gravosas. Para ello pone límites a las posibles estipulaciones contractuales de las partes, sobre todo en lo que concierne a la voluntad del empresario, que tienden a preservar el principio de libertad de trabajo y el juego de la libre y lícita concurrencia.

El resultado de este intento de conciliación de intereses contrapuestos, que en reiteradas ocasiones llega a alcanzar la categoría de conflicto de derechos, es la normativa aplicable a las relaciones competenciales que se predican entre empresarios y trabajadores.

Concretamente, esta materia tiene un tratamiento general para todos los trabajadores por cuenta ajena, que se contiene en el Estatuto de los Trabajadores, y unas formulaciones específicas para determinadas relaciones especiales de trabajo, que se regulan en los distintos Reales Decretos, reguladoras de esas relaciones laborales de carácter especial, en el Real Decreto 1382/1985, de 1 de agosto, por el que se regula 
la relación laboral de carácter especial del personal de alta dirección ${ }^{1}$, el Real Decreto 1438/1985, de 1 de agosto, por el que se regula la relación laboral de carácter especial de las personas que intervengan en operaciones mercantiles por cuenta de uno o más empresarios, sin asumir el riesgo y ventura de aquéllas, el Real Decreto 1006/1985, de 26 de junio, por el que se regula la relación laboral especial de los deportistas profesionales, el Real Decreto 1435/1985, de 1 de agosto, por el que se regula la relación laboral especial de los artistas en espectáculos públicos o el Real Decreto 1331/2006, de 17 de noviembre, por el que se regula la relación laboral de carácter especial de los abogados que prestan servicios en despachos de abogados, individuales o colectivos.

Así, las normas laborales prevén y regulan situaciones, circunstancias y pactos perfectamente diferenciados, con distintas limitaciones y distinta efectividad práctica que pueden ser clasificados en cuatro grandes apartados:

Formulaciones generales: artículos 5.c) ET, 9 Real Decreto 1438/1985, de 1 de agosto y 5.3 Real Decreto 1331/2006, de 17 de noviembre

$\checkmark$ Normas destinadas a la protección de la clientela del empresario durante la vigencia de la relación laboral. En ellas se incluyen la prohibición de concurrencia (artículos 21.1 ET y 8.1 Real Decreto 1382/1985, de 1 de agosto), pactos de plena dedicación o también denominados pactos de dedicación exclusiva (artículos 21.3 ET, 8.2 Real Decreto 1382/1985, de 1 de agosto y 6.4 Real Decreto $1435 / 1985$, de 1 de agosto) y pactos de permanencia (art. 21.4 ET).

$\checkmark$ Normas destinadas a la protección de la clientela del empresario, después de extinguido el contrato de trabajo y concluida la relación laboral. Son los pactos de no competencia o también llamados pactos de no concurrencia (artículos 21.2 ET, 8.3 Real Decreto 1382/1985, de 1 de agosto y 10.4 Real Decreto 1438/1985, de 1 de agosto).

$\checkmark$ Consecuencias jurídicas cuando se incumplen estas obligaciones (art. 54.2.d ET).

\section{EL CONCEPTO DE COMPETENCIA DESLEAL}

${ }^{11}$ Sentencia del Tribunal Superior de Justicia (STSJ) Madrid 25 de abril de 2011. 
La concurrencia, en el sentido de pluriempleo, como posibilidad de que el trabajador por cuenta ajena pueda desarrollar fuera de su horario laboral por una actividad por cuenta propia o ajena, no es contraria a la ley². De la relación de trabajo no deriva, sin más, una cláusula de exclusiva por la que el trabajador se vea impedido de trabajar con cualquier otro empresario, o sencillamente por cuenta propia.

Por consiguiente, será lícita, en principio cualquier actividad paralela o complementaria del trabajo principal que el trabajador realice. Así, por ejemplo, ha declarado la jurisprudencia que la concurrencia desleal no puede darse cuando se realicen actividades ociosas o deportivas, aunque se trate de pilotos de aviación, a los que no se les puede impedir hacer las actividades que quieran en momentos de descanso ${ }^{3}$.

Lo prohibido legalmente es sólo aquella o aquellas actividades que pueda desarrollar el trabajador susceptible de ser estimada como competencia desleal. De esta manera, la ilicitud surgirá únicamente en el momento en que sea estimable la competencia desleal. Los límites de las posibles actividades paralelas o complementarias lícitas de los trabajadores acaban allí donde comienza el ámbito de actuación del empresario.

Esta prohibición de concurrencia también se encuentra presente en diversos países de la Unión Europea ${ }^{4}$. Así, en Alemania, aunque no existe una norma específica, esta prohibición deriva de la obligación de buena fe regulada en el parágrafo 242 del Código civil, que para su concreta aplicación acoge la regulación contenida en el parágrafo 60.1 del Código de comercio al disponer que al trabajador no le está permitido ni realizar actividades mercantiles ni realizar negocios por cuenta propia o ajena en el sector de actividad del principal sin su consentimiento. En todo caso, el fundamento del derecho de la competencia utiliza el término leinstungswettberwerb que puede ser traducido como competencia por eficiencia, o sea por una necesidad que la lucha

\footnotetext{
2 Entre muchas sentencias cabe citar la STSJ Cataluña 14 de febrero de 1992, STSJ Asturias 19 de abril de 1996 y STSJ Extremadura 4 de marzo de 2010.

${ }^{3}$ STSJ Baleares 10 de mayo de 1999.

${ }^{4}$ También otros países presentan esta regulación, aunque normalmente por haberlo importado de Estados de la Unión Europea, como puede ser Argentina o Méjico. Entre los autores que estudian esta figura en estos países véase, en el primer caso, DE LITALA, 1946, pág. 176; DE LA CUEVA, 1970, págs. 576.
} 
concurrencial se desarrolle sobre prestación más eficientes que la de los competidores (MOLINA BLAZQUEZ, 1993, p.266-267). En Francia, de acuerdo con las reglas generales de los artículos 1134 y 1135 del Código civil, se prohíbe esta concurrencia 5 . En Italia el art. 2105 del Código civil impide al trabajador gestionar negocios ajenos por cuenta propia o de tercero, en concurrencia con el empresario 6 . Finalmente, en Portugal, el art. 136 del Código de Trabajo, establece este deber del trabajador como una cláusula de limitación de libertad de trabajo.

En este orden de cosas, concurrencia será la dedicación a actividades de la misma o similar naturaleza o rama de la producción de las que se está ejecutando en virtud de contrato de trabajo, por lo que, a sensu contrario, es perfectamente lícita "cualquier actividad paralela del trabajador, incluso en la misma rama de la producción, siempre que esa actuación no resulte competitiva con la de su empresario o constituya una colaboración con un competidor ${ }^{7 "}$ o cuando se trate de distinta actividad económica y diferente red comercial ${ }^{8}$.

Así, entre los varios casos que la jurisprudencia ha considerado que no había concurrencia desleal cabe citar la realización de trabajos como catedrático auxiliar de universidad $^{9}$, la prestación de servicios por la noche en un periódico, como oficial de cierre y, por la tarde aprovechando sus horas libres, se dedicaba a otra función como dependiente de un taller de encuadernación ${ }^{10}$, la conducción de autobuses siendo

\footnotetext{
${ }^{5}$ Sobre este tema véase, entre otros, DURAND, 1950, págs. 586; CAMERLYNCK, 1982, págs. 253; COUTURIER, 1994, pág. 329 y MIALON, 1996, pág. 47.

${ }^{6}$ Sobre este tema véase, entre otros muchos autores, BARASSI, 1917, págs. 151; PERSIANI, 1966, pág. 219; D'EUFEMIA, 1969, pág. 62; RIVA SANSEVERINO, 1971, págs. 233; RIVA SANSEVERINO, y MAZZONI, 1971, págs. 257; ARDAU, 1972, págs. 903-905, RIVA-SANSEVERINO, L, 1977, pág. 384, SANTORO PASSARELLI, 1978, págs. 184-185; PERA, 1984, págs. 602; SCOGNAMIGLIO, 1992, pág. 415; GALANTINO, 1992, págs. 342; CENDON, 1992, pág. 174.

7 Sobre este tema véase CASTIÑEIRA FERNANDEZ, 1977, pág. 129. Este tema también ha sido tratado por la jurisprudencia, entre la que se debe destacar, entre las sentencias del Tribunal Supremo, la STS 10 de abril de 1982, STS 3 de junio de 1986 y 22 de octubre de 1990. Asimismo, entre las sentencias del Tribunal Central de Trabajo, véase la STCT 18 de febrero de 1978, STCT 27 de noviembre de 1979, STCT 25 de enero de 1980, STCT 8 de febrero de 1980, STCT 25 de junio de 1980 y STCT 29 de octubre de 1980.

8 STSJ Castilla y León/Burgos 29 de marzo de 2007. En cambio la STSJ Cantabria 12 de julio de 2006 entiende que es concurrente la actividad cuando se trata de la misma actividad comercial, aunque vaya dirigida a diferentes clientes.

${ }^{9}$ STS 8 de marzo de 1948.

10 STS de 12 de enero de 1960.
} 
conductor de taxis ${ }^{11}$, la conducción de ambulancias en dos empresas del mismo sector ${ }^{12}$, la simple publicación de un libro ${ }^{13} \mathrm{o}$ en caso de trabajador de una entidad financiera que es fundador de una empresa de tecnologías de la información e informáticas ${ }^{14}$.

Esta misma consecuencia se ha de aplicar en aquellos casos que, pudiendo ser considerados bajo un estricto análisis objetivo de conductas de competencia desleal son autorizadas por la empresa a la que con su comportamiento el trabajador que las lleva a cabo puede perjudicar ${ }^{15}$. En cambio, esta nota de tolerancia no se aprecia cuando un jefe de ventas de una empresa es a su vez socio y administrador de otra empresa con la misma actividad, con independencia que tanto la constitución de la sociedad como el nombramiento como administrador sean previos a su contratación, ya que esta circunstancia no revela que la empresa tuviera conocimiento de estos hechos ${ }^{16}$ o cuando existe prohibición expresa de la empresa ${ }^{17}$.

Es independiente que esta actividad de competencia se realice bien por cuenta propia $^{18}$, por cuenta ajena ${ }^{19}$ o por medio de un contrato de agencia ${ }^{20}$, ya que lo esencialmente relevante es que el trabajador, sin autorización del empresario, genere con sus actos intereses contrapuestos ${ }^{21}$, ya que ofrece a la misma clientela -actual o potencial-, bienes o servicios de igual especie o carácter, y perjudique a aquél, sin que sea necesario que el perjuicio sea efectivo y real, bastando con que sea potencial y que

\footnotetext{
${ }^{11}$ Sentencia del Tribunal Central de Trabajo (STCT) 14 de enero de 1978 y STCT 7 de marzo de 1978.

12 STSJ Madrid13 de julio de 2006.

${ }^{13}$ STS 20 de julio de 1990.

14 STSJ Madrid 21 de febrero de 2018

15 STSJ Madrid 1 de marzo de 2013.

${ }^{16}$ STSJ Andalucía/Málaga 21 de octubre de 2013.

17 STSJ Cataluña 25 de enero de 2008.

18 STS 15 de enero de 1968 y STS 11 de noviembre de 1969. Igualmente, STSJ Cataluña 21 de abril de 1992, STSJ Galicia 20 de junio de 1992 y STSJ Galicia 1 de julio de 1992.

${ }_{19}$ Sobre este tema véase la STS de 27 de noviembre de 1960 y STS 10 de noviembre de 1965. Asimismo, STCT 28 de mayo de 1975, STCT 4 de junio de 1977, STCT 16 de junio de 1977, STCT 27 de junio de 1977, STCT 15 de diciembre de 1978, STCT 2 de febrero de 1979, STCT 10 de diciembre de 1980 y STCT 29 de enero de 1981.

20 STSJ Asturias 6 de noviembre de 2009.

${ }^{21}$ Respecto a esta materia véase la STS 9 de marzo de 1975 y STS 21 de junio de 1976. De la misma manera, STCT 13 de febrero de 1973, STCT 5 de diciembre de 1973, STCT 6 de junio de 1974, STCT 25 de octubre de 1974, STCT 18 de septiembre de 1975, STCT 5 de julio de 1977, STCT 17 de mayo de 1978, STCT 11 de noviembre de 1980 y STCT 23 de junio de 1981. Asimismo, AGUILERA IZQUIERDO, "Concurrencia desleal: empresa constituida por cónyuge de la trabajadora. Prescripción de las faltas laborales", Aranzadi Social, Volumen IV, 1999, págs. 2813 ss.
} 
el perjuicio se presume en todo trabajo en actividad idéntica o similar ${ }^{22}$, máxime si se desarrolla, por ejemplo, en la misma localidad ${ }^{23}$.

La concurrencia desleal que prohíbe el artículo 21.1 ET comprende tanto las actividades competitivas que pueda realizar directamente el empleado, como su simple colaboración con terceros competidores del empresario.

Si la competencia la lleva a cabo personalmente el trabajador, el supuesto no plantea problemas interpretativos. Constituye conculcación del deber laboral previsto en el artículo 5.d) ET y del mandato del artículo 21.1 de la propia Ley, pudiendo ser sancionado con un despido disciplinario en los términos previstos en el artículo 54.2.d), por quebranto de la buena fe contractual, cuyo análisis jurídico es competencia del orden jurisdiccional social, ya que se trata de un incumplimiento de las obligaciones inherentes al contrato de trabajo ${ }^{24}$.

Por el contrario, la licitud de la conducta competencial cuando el trabajador es propietario de acciones o participaciones de sociedades competidoras de su empresa, o sea socio colectivo o comanditario de sociedades competitivas, es cuestión más delicada. Doctrinal y jurisprudencialmente se viene admitiendo que la simple posesión de títulos de propiedad en una sociedad de capital competidora no constituye competencia desleal si la actuación del empleado es meramente inversionista, sin posibilidades de decisión personal ${ }^{25}$.

En cambio, queda incurso en la prohibición el trabajador que ostente un cargo de gestión, por ejemplo, si el trabajador es accionista o propietario de una parte relevante del tanto por ciento de las participaciones sociales, además de apoderado y elemento

\footnotetext{
22 STS 8 de marzo de 1991 y STS 22 de noviembre de 2007. Igualmente, STSJ Madrid de 24 de febrero de 1993, STSJ Castilla y León/Valladolid de 30 de marzo de 1993, STSJ Madrid de 14 de abril de 1994 y STSJ Baleares de 22 de marzo de 1997.

${ }^{23}$ Sobre este tema véase STS 11 de junio de 1986, STS 16 de junio de 1986 y STS 22 de febrero de 1990. En el mismo sentido, STCT 8 de abril de 1975, STCT 7 de junio de 1975, STCT 30 de septiembre de 1975, STCT 18 de mayo de 1978, STCT 30 de junio de 1981 y STCT 16 de diciembre de 1982. Igualmente, STSJ Galicia 15 de septiembre de 1994 y STSJ Galicia 18 de mayo de 1995.

${ }^{24}$ STS 4 de mayo de 2017.

${ }^{25}$ Como ejemplo, en la STSJ Comunidad Valenciana de 17 de julio de 1996, se le imputa a una trabajadora una consecuencia ilícita cuando resulta que ella adquirió las participaciones de la empresa de la competencia (el 28,7\%) el mismo día y en el mismo acto notarial en que el empresario para el que iba a prestar servicios después adquiría el $71 \%$ restante. En esta situación está claro que su empresario en la empresa en la que presta servicios era a su vez socio mayoritario en la otra empresa, con lo que hace imposible jurídicamente calificar de transgresora de la buena fe contractual la conducta de la citada trabajadora, y apoyar en ello la decisión empresarial de prescindir de sus servicios por despido disciplinario.
} 
activo de otra empresa y ha realizado funciones en esta empresa ${ }^{26}$, o esté en condiciones de controlar el nombramiento de los órganos gestores, por ejemplo si ostenta el cargo de presidente del consejo de administración ${ }^{27}$, de vicepresidente ${ }^{28}$, es administrador y accionista único ${ }^{29}$, de secretaria del consejo de administración de sociedad $^{30}$, simple consejero ${ }^{31}$ o como accionista ${ }^{32}$.

En las sociedades colectivas y comanditarias, dada su naturaleza personalista y su forma de gobierno, hay que entender siempre desleal la participación del trabajador, cuando por razón de la actividad desplegada, sean empresas competidoras ${ }^{33}$.

En cuanto a la colaboración del trabajador con terceros competidores del empresario, hay que entenderla incursa en la prohibición cualquiera que sea la forma en que se auxilie a la actividad competitiva (ALONSO GARCIA, 1960, p.382), ya sea a título oneroso o gratuito ${ }^{34}$, ya a través de una relación jurídico-mercantil o labora ${ }^{35}$. Además, la prohibición afecta a los negocios que entren dentro del ámbito del objeto social de la empresa, siempre que el objeto estatutario se corresponda con la actividad realmente llevada a cabo ${ }^{36}$.

${ }^{26}$ En este tema véase STS 2 de noviembre de 1973, STS 11 de mayo de 1979, STS 11 de mayo de 1985, STS 2 de julio de 1985 y STS 7 de marzo de 1990. De la misma manera, STCT 20 de abril de 1978. Así como STSJ Comunidad Valenciana de 16 de enero de 1996.

27 STS 20 de marzo de 1967, STS 19 de junio de 1975, STS 23 de diciembre de 1978 y STS 23 de junio de 1982. De la misma manera, STSJ Cataluña de 30 de abril de 1993 y STSJ Comunidad Valenciana 20 de febrero de 1996.

${ }^{28}$ STS 25 de octubre de 1983. Igualmente, STSJ Canarias/Las Palmas 8 de junio de 1995.

29 STSJ Madrid 1 de marzo de 2013.

30 STS 2 de marzo de 1981.

${ }^{31}$ STS 22 de septiembre de 1988. Igualmente, STSJ Baleares 30 de junio de 1998.

32 STS 28 de octubre de 1980, STS 30 de septiembre de 1982, STS 7 de marzo de 1990 (Ar. 1773) y STS 13 de julio de 1990. Igualmente, STSJ Madrid 12 de mayo de 1992 y STSJ País Vasco 25 de mayo de 1999.

${ }^{33}$ La STS 23 de enero de 1946 declaró que los trabajadores eran despedidos por haber adquirido acciones de la sociedad, no para sí, aunque no aparezca para quién, al margen de las medidas adoptadas por la empresa para evitar el peligro de desaparición del sistema cooperativista con que se fundó.

34 En cambio, no existe concurrencia desleal, según la STSJ Comunidad Valenciana 14 de octubre de 2008, STSJ Andalucía/Granada 29 de abril de 2011 y STSJ Andalucía/Málaga 16 de noviembre de 2013, en un supuesto que consiste en una colaboración puntual, anecdótica y desinteresada por amistad y sin contraprestación alguna.

${ }^{35}$ Sobre este tema véase STS 16 de octubre de 1982, STS 2 de noviembre de 1982, STS 8 de noviembre de 1982 y STS 4 de diciembre de 1982. Igualmente, STCT 2 de diciembre de 1975 y STCT 21 de diciembre de 1982. Asimismo, STSJ Navarra de 30 de septiembre de 1993.

${ }^{36}$ STSJ Navarra 5 de junio de 2008, STSJ Cataluña 7 de julio de 2011 y STSJ Galicia 19 de marzo de 2012. 
Así, para que una actividad pueda ser calificada como de desleal cabe que concurran los siguientes tres requisitos.

En primer lugar, la existencia de dos empresas que realicen actividades que pueden llegar a ser competitivas. En este caso, uno de los elementos que permiten comprobar esta identidad deriva de los estatutos sociales de ambas empresas ${ }^{37}$. Ahora bien, en caso de disparidad, o simplemente de distinta amplitud, entre objeto social y actividad de la empresa, ha de entenderse que la prohibición afecta sólo a los negocios competidores de la actividad de la empresa, y no a aquellos otros que pudiendo estatutariamente realizar, no lleva a cabo.

En segundo lugar, estas empresas deben ofrecer los mismos o equivalentes bienes o servicios ${ }^{38}$. El problema surge a la hora de comparar los bienes o servicios para poder predicar de ellos la igualdad o similitud. De esta manera no sirve que las empresas en conflicto pertenezcan a la misma rama productiva, sino que hay que acudir a los propios bienes y servicios ${ }^{39}$, como puede observarse en los siguientes tres ejemplos: en el primero, se analiza un supuesto en el que se hallan inmersa dos empresas que venden productos de laboratorio ${ }^{40}$, en el segundo, se refiere a dos empresas de prendas de punto, pero una se dedica a confección para adultos y la otra para niños ${ }^{41}$, mientras que en el tercero, ambas empresas están en el mismo sector empresarial, pero se comercializan productos en los que la empresa no está interesada ${ }^{42}$.

\footnotetext{
37 STSJ Galicia de 25 de marzo de 1992, STSJ Madrid de 12 de mayo de 1992, STSJ Madrid de 10 de noviembre de 1995, STSJ Madrid de 4 de octubre de 1996 y STSJ Cataluña de 31 de octubre de 1996.

${ }^{38}$ Entre las innumerables sentencias que tratan este tema, véase STS 5 de marzo de 1945, STS 23 de enero de 1946, STS 10 de junio de 1955, STS 8 de marzo de 1956, STS 15 de marzo de 1956, STS 16 de diciembre de 1957, STS de 9 de mayo de 1960, STS 17 de febrero de 1966, STS 10 de febrero de 1976, STS 7 de noviembre de 1985 y STS 6 de noviembre de 1986. Asimismo, STCT 25 de octubre de 1973, STCT 17 de noviembre de 1973, STCT 28 de enero de 1975 y STCT 4 de abril de 1975. Igualmente, STSJ Castilla y León/Valladolid 30 de marzo de 1993, STSJ País Vasco de 26 de marzo de 1996 y STSJ Cataluña 22 de septiembre de 2011.

${ }^{39}$ En este tema véase STS 29 de noviembre de 1946, STS 8 de marzo de 1948, STS 18 de enero de 1952, STS 30 de octubre de 1953, STS 24 de febrero de 1958, STS 27 de junio de 1958, STS 24 de junio de 1959, STS 26 de junio de 1959, STS 2 de diciembre de 1959, STS de 22 de abril de 1960, STS 7 de febrero de 1967 y STS 19 de septiembre de 1985. En el mismo sentido, STCT 4 de abril de 1973, STCT 26 de abril de 1973, STCT 28 de mayo de 1973, STCT 1 de julio de 1975 y STCT 15 de febrero de 1977. Igualmente, STSJ Galicia 13 de marzo de 2015.

40 STSJ Comunidad Valenciana 12 de abril de 1994.

41 STSJ Galicia 21 de junio de 1993.

42 STSJ Madrid 24 de enero 2006.
} 
De la misma manera, pueden haber actividades idénticas que no supongan concurrencia, por ejemplo, en el caso de limpiadora que además realiza trabajos de limpieza para otra empresa ${ }^{43}$, si se trata de dos hoteles en localidades alejadas entre $\mathrm{sí}^{44}$ o en supuestos de difícil competencia, ya que se trata de lavado automatizado de coches, y además se encuentran en poblaciones separadas ${ }^{45}$.

En tercer lugar, estas empresas se han de dirigir a un mismo mercado y sobre un mismo círculo potencial de clientes ${ }^{46}$, bien se trate de cliente intermedios ${ }^{47}$, por ejemplo empresas a las que provee la empresa para la que presta servicios el trabajador o simplemente clientes finales ${ }^{48}$.

Esta es quizás la verdadera esencia que permite definir la concurrencia desleal, de manera que si no existen actividades dirigidas a la misma clientela no habrá competencia deslea ${ }^{49}$, como por ejemplo, en un caso en el que, aunque era la misma rama o actividad, era distinta la clientela, por lo que no existían intereses contrapuestos ${ }^{50}$. Sin embargo, esta apreciación también plantea muchos problemas.

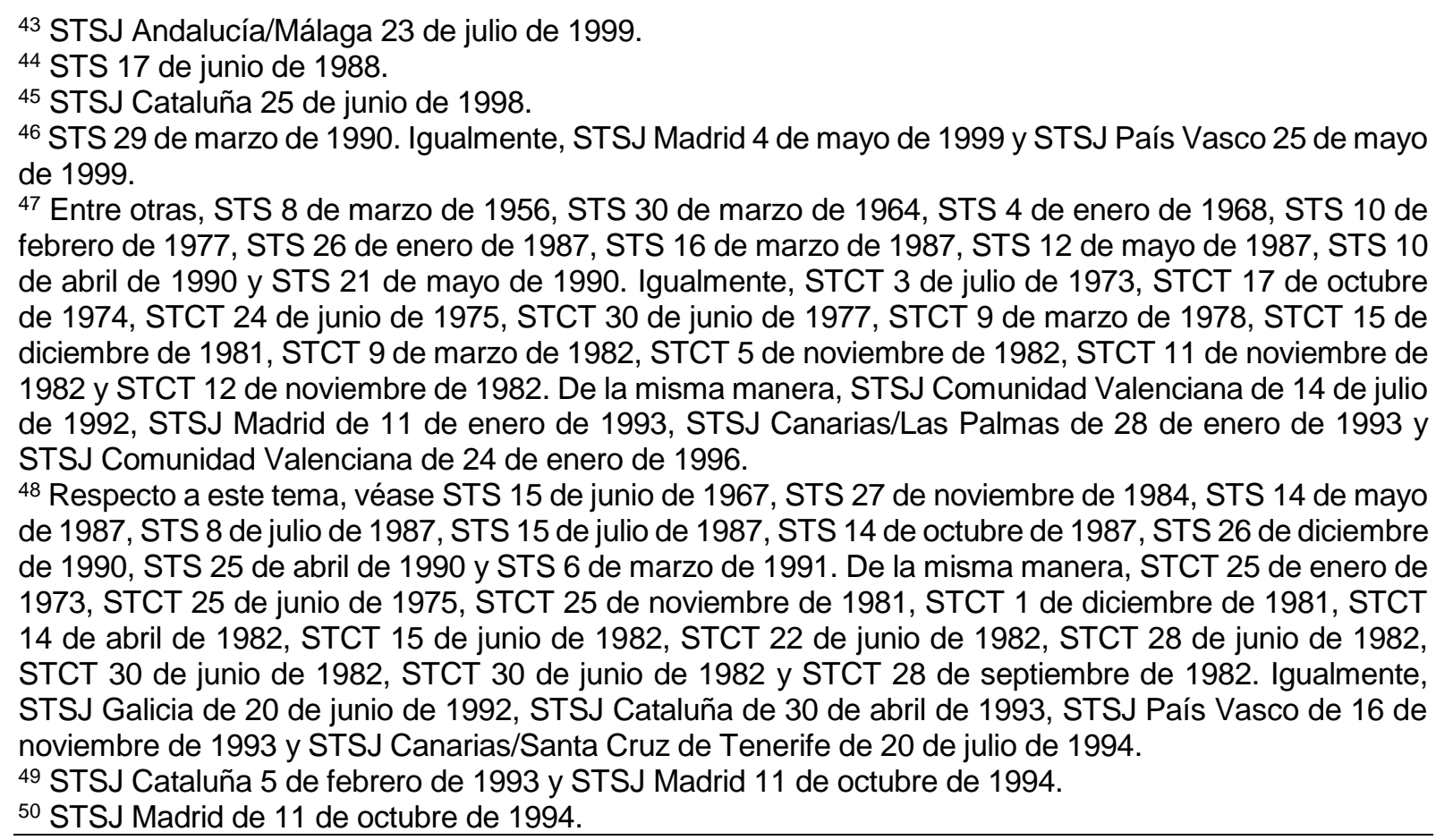


Esta misma valoración ha de predicarse de situaciones en las que la captación no se realiza de clientes, sino de patrocinadores, aprovechando la posición del trabajador de director ${ }^{51}$.

Problema conexo e importante es determinar el momento en que hay que considerar la actividad del empresario, en cuanto que este es un concepto dinámico que puede variar a lo largo de la vida de la relación de trabajo.

En principio la actividad a calificar como objeto de la prohibición es la desarrollada por el empresario en el momento de la conclusión del contrato de trabajo. Ahora bien, si posteriormente, en el curso de la ejecución del contrato, se ampliara la actividad del empresario, habría que distinguir dos situaciones diferenciadas.

En primer lugar, la de aquellos trabajadores que estuvieran realizando una actividad paralela y complementaria, no competitiva en el momento de la celebración del contrato, y que pasa a serlo en méritos de la ampliación de actividades de su empresario. En este caso se produciría una auténtica novación objetiva del contrato de trabajo, que como tal y para su licitud, debería ser voluntaria y compensada. En segundo lugar, la de quienes no desarrollaran este tipo de actividades, en cuyo caso puede estimarse simplemente ampliado el alcance de la prohibición legal.

De esta manera, una vez analizados estos fundamentos, cabe afirmar que la razón de ser del precepto legal estudiado, además de la protección de la clientela ${ }^{52}$, es la protección de los intereses específicos del empresario respecto a la reserva de los secretos de la empresa.

La prohibición de revelar secretos sí se regula en alguno de los ordenamientos jurídicos de varios países de la Unión Europea. Concretamente el art. 2105 del Código civil italiano determina la obligación del trabajador de no divulgar noticias respecto de la organización o de los métodos de producción de la empresa, o hacer uso de ellos de modo que le pueda ocasionar un perjuicio ${ }^{53}$. De la misma manera, el art. 128.1.f) del

\footnotetext{
51 STSJ Madrid 21 de junio de 2018.

52 STSJ Cantabria 1 de diciembre de 1998.

53 Sobre este tema véase RIVA SANSEVERINO, y MAZZONI, Nuovo trattato di Diritto del Lavoro, Pádua, (CEDAM), 1971, págs. $250 \mathrm{ss,} \mathrm{ICHINO,} \mathrm{Diritto} \mathrm{a} \mathrm{la} \mathrm{riservatezza} \mathrm{e} \mathrm{diritto} \mathrm{al} \mathrm{segreto} \mathrm{nel} \mathrm{rapporto} \mathrm{di} \mathrm{lavoro,}$ Milán, (Dott. A. Giuffrè Editore), 1979, págs. 206 ss, PERA, Diritto del Lavoro, Pádua, (CEDAM), 1984, págs. 604-605, GHIDINI, Diritto del Lavoro, Padua, (CEDAM), 1987, pág. 357, SCOGNAMIGLIO, Diritto
} 
Código de Trabajo Portugués contempla entre los deberes del trabajador la no divulgación de información referente a su organización, métodos de producción o negocios. En cambio en otros países, entre los que se puede destacar Alemania ${ }^{54}$ y Francia ${ }^{55}$, igual que sucede en España, no existe una regulación específica y la jurisprudencia ha derivado este deber directamente de la obligación de buena fe.

En España, la norma mercantil define la violación de secretos como la divulgación o explotación en provecho propio o de un tercero, sin autorización de su titular, de cualquier especie de secreto empresarial al que haya tenido acceso legítimamente aunque con deber de reserva, o ilegítimamente ${ }^{56}$, y aunque no exista norma expresa, también se incluye en la obligación de buena fe que ha de asumir el trabajador.

El secreto profesional consiste en no comunicar noticias de la empresa que puedan perjudicar a ésta y beneficiar a otras; así cabe incluir los secretos de fabricación, los datos de la organización o la técnica de producción (BAYON CHACON; PEREZ BOTIJA, 1958-1959, p.217). Esta prohibición ha de extenderse no sólo a los de carácter estrictamente profesional, sino, más ampliamente, a aquellos que, afectando a la explotación o a los negocios, como consecuencia del ejercicio de la profesión o la prestación de los servicios, pero justamente por cuenta del empresario en cuyo servicios los datos o noticias secretas sean conocidos (ALONSO GARCIA, 1960, p.381); sin embargo, algunos autores han entendido que no puede, por ejemplo, hacer referencia a la posibilidad que tiene el trabajador de denunciar determinadas conductas de su empresario (FERNANDEZ LOPEZ, 1983, p.230).

Se refiere, normalmente, a actividades que se desarrollan dentro del mismo plano en que efectúa las suyas la empresa principal por incidir sobre un mismo mercado y sobre un mismo círculo potencial de clientes, realizándose aquéllas con olvido de las exigencias de la buena fe, mediante el aprovechamiento de datos internos de la empresa

del Lavoro, Nápoles, (Jovene Editore), 1992, págs. 416-417 y GALANTINO, Diritto del Lavoro, Turín, (Giappichelli Editore), 1992, págs. 344 ss.

${ }^{54}$ En cuanto a la situación en este país véase WENIGER, 1994, págs. 55.

${ }^{55}$ Respecto a este país véase COUTURIER, 1994, pág. 329 y MIALON, 1996, págs. 48-49.

56 STSJ Canarias/Las Palmas 28 de enero de 1993, STSJ Madrid 10 de enero de 1994 y STSJ Cantabria 5 de julio de 1996. 
que son conocidos por su trabajo en ésta y que cuando se refieren a un sistema organizativo o de producción o versan sobre la relación de sus proveedores o clientes, pueden ocasionar un potencial perjuicio a aquélla (HIDALGO RUA; DEL VAL ARNAL, 1991, p.203), por alterar el juego de la libre competencia, proporcionando una situación de ventaja para la segunda actividad ${ }^{57}$.

La creación de este daño para el empresario por parte del trabajador, que es al final la cuestión fundamental a analizar, se puede crear por medio de un número muy amplio de $\operatorname{conductas}^{58}$, entre las que cabe destacar el descubrimiento del crédito de los cliente en entidades bancarias ${ }^{59}$, la divulgación de los escritos, entregándolos a personas ajenas al servicio de contabilidad de la empresa ${ }^{60}$, procurarse copias del fichero de clientes, teniendo ya anunciado su propósito de abandonar la empresa y obteniéndolas en ausencia del director ${ }^{61}$, fotocopiar documentos de manera fraudulenta que son aportados en juicio contra la empresa ${ }^{62}$, ocultar a la empresa subcontratas, promoviendo falsedades en los documentos ${ }^{63}$ o entregar muestrarios y listados de clientes a la empresa competidora ${ }^{64}$.

\section{EL DAÑO COMO ELEMENTO FUNDAMENTAL}

Competencia y perjuicio son conceptos inseparables. De esta manera, y aunque el art. $21 \mathrm{ET}$ no lo contenga como elemento a tener en cuenta, a diferencia del anterior art. 73 de la Ley de Contrato de Trabajo de 1944, no se concibe que la simple entrada

\footnotetext{
57 STSJ Andalucía/Málaga de 7 de noviembre de 1994.

${ }^{58}$ Sobre el daño en general véase STS 1 de marzo de 1946. Igualmente, OLMO FERNANDEZ-DELGADO, 2000 , págs. 69.

${ }^{59}$ STCT 2 de octubre de 1973.

60 STS 21 de mayo de 1975. Igualmente, STCT 29 de octubre de 1976.

61 STS 18 de junio de 1973, STS 23 de diciembre de 1983, STS 20 de julio de 1988, STS 3 de octubre de 1988. De la misma manera, STSJ Canarias/Las Palmas de 28 de enero de 1993 y STSJ Madrid 17 de septiembre de 1998.

62 STS 6 de abril de 1990 y STS 11 de junio de 1990. Igualmente, STCT 16 de octubre de 1974 y STCT 11 de marzo de 1981. De la misma manera, véase la STSJ Baleares 15 de septiembre de 1998.

63 STS 17 de julio de 1990.

${ }^{64}$ STS (Sala Civil) 11 de febrero de 1993. De la misma manera, STSJ Madrid de 16 de marzo de 1992 y STSJ Galicia 23 de junio de 1994. En esta misma línea, ROJAS RIVERO, La libertad de expresión del trabajador, Madrid, (Trotta), 1991, págs. 70 ss.
} 
de un empresario en el ámbito de actuación de otro pueda no ocasionarle perjuicio ${ }^{65}$. Por esta razón la jurisprudencia ha entendido que la verdadera razón de ser de esta limitación es la protección de los intereses del empresario ${ }^{66}$.

El perjuicio puede consistir en una consecuencia materializada económicamente, por ejemplo, una disminución de las ventas o una disminución de la cuota de penetración en el mercado, así como un daño potencial, de manera que no se pueda calcular un perjuicio concreto ${ }^{67}$, como por ejemplo, en un supuesto que un trabajador de Cruz Roja que trabaja como gerente de la DYA y consigue la adjudicación del concurso público al que concurría su empresa ${ }^{68}$.

Hay que tener en cuenta que para la determinación del daño es preciso atender a los elementos objetivos de la conducta del trabajador, sin que pueda ni deba acudirse a ningún tipo de conjeturas, ya que lo que se analiza es si la actividad del trabajador en la otra empresa, revela una transgresión de la buena fe contractual en el servicio que presta a la empresa ${ }^{69}$.

En todo caso, este perjuicio potencial se presume iuris tantum cuando se desarrolla un trabajo de idéntica o similar actividad en una misma localidad ${ }^{70}$ o próximas

65 Sobre este tema véase BAYON CHACON y PEREZ BOTIJA, 1958-1959, pág. 219, BORRAJO DACRUZ, 1960, pág. 96; RODRIGUEZ-PIÑERO y BRAVO-FERRER, 1977, pág. 20 y CASTIÑEIRA FERNANDEZ, 1977, pág. 142.

${ }^{66}$ STS 19 de octubre de 1988. Igualmente, STSJ Madrid 25 de junio de 1991, STSJ Asturias 10 de febrero de 1995 y STSJ Extremadura 5 de abril de 1995.

${ }^{67}$ STS 21 de septiembre de 1984, STS 20 de septiembre de 1988, STS 19 de octubre de 1988, STS 18 de julio de 1989, STS 22 de octubre de 1990, STS 28 de noviembre de 1990 y STS 8 de marzo de 1991. De la misma manera, STCT 11 de julio de 1973, STCT 11 de octubre de 1973, STCT 20 de septiembre de 1974 y STCT 9 de diciembre de 1981. Igualmente, STSJ Cataluña de 5 de marzo de 1992, STSJ Cantabria de 14 de octubre de 1992, STSJ Madrid de 18 de noviembre de 1992, STSJ Andalucía/Málaga de 31 de enero de 1993, STSJ La Rioja de 8 de febrero de 1993, STSJ Comunidad Valenciana de 22 de junio de 1993, STSJ Cataluña de 22 de junio de 1993, STSJ Andalucía/Málaga de 23 de julio de 1993, STSJ Comunidad Valenciana de 12 de abril de 1994, STSJ Aragón de 16 noviembre de 1994, STSJ Castilla y León/Burgos de 21 de noviembre de 1995, STSJ Cataluña de 29 de diciembre de 1995, STSJ Cataluña de 14 de septiembre de 1996 y STSJ Cataluña 5 de noviembre de 1999.

68 STSJ Extremadura 17 de mayo de 2011.

69 STSJ Cataluña de 14 de febrero de 1992.

70 Sobre este tema véase la STS 6 de noviembre de 1979. Igualmente, STCT 27 de noviembre de 1981 y STCT 11 de octubre de 1973. De la misma manera, STSJ Cataluña 5 de marzo de 1992, STSJ Cantabria 12 de diciembre de 1994, STSJ Galicia de 18 de mayo de 1995, STSJ Asturias de 19 de abril de 1996, STSJ Andalucía/Málaga 17 de abril de 1998 y STSJ Cataluña 25 de junio de 2013. 
si pueden considerarse dentro de un mismo ámbito comercial ${ }^{71}$, salvo que pueda demostrarse que no se ha producido desvío de clientela ${ }^{72}$, como por ejemplo, en un supuesto en el que la actividad de las empresas es de difícil competencia, ya que se trata de lavado automatizado de coches, y además se encuentran en poblaciones separadas ${ }^{73}$.

La dificultad en esta materia radica en evaluar, y sobre todo en probar, el perjuicio efectivo sufrido por el empresario, en orden a exigir su reparación $n^{74}$.

Esta dificultad ha llevado a la jurisprudencia a concluir que la violación de la prohibición es independiente de un daño efectivo al empresario, siendo suficiente el daño potencial ${ }^{75}$. Esta es la razón por la que puede considerarse que lo característico es el elemento intencional revelador de una premeditada conducta desleal del trabajador respecto de la empresa ${ }^{76}$, no el daño efectivamente producido, que no sólo remunera un trabajo, sino que también le facilita medios para adquirir experiencia y perfeccionamiento profesional que luego aquél pretende utilizar en su propio provecho ${ }^{77} \mathrm{y}$ en demérito $\mathrm{o}$ perjuicio para los intereses de su empresa ${ }^{78}$.

Este daño se puede producir, ya actúe el trabajador que lleva a cabo la actividad competencial con negligencia en el cumplimiento de sus obligaciones o con algún tipo de intencionalidad, por ejemplo, cuando aprovechándose de la experiencia profesional

\footnotetext{
71 STS 25 de enero de 1984, STS 16 de diciembre de 1986, STS 26 de enero de 1988, STS 3 de noviembre de 1988, STS 17 de julio de 1989 y STS 17 de diciembre de 1990. Igualmente, STSJ Castilla y León/Valladolid de 5 de diciembre de 1995 y STSJ País Vasco de 26 de marzo de 1996.

72 STSJ País Vasco 16 de noviembre de 1993 y STSJ Navarra 28 de julio de 2008.

${ }^{73}$ STSJ Cataluña 25 de junio de 1998.

74 STS 16 de junio de 1982. Igualmente, STSJ Cataluña de 14 de febrero de 1992, STSJ Galicia de 21 de junio de 1993, STSJ Madrid de 7 de septiembre de 1993 y STSJ Cataluña 30 de octubre de 2007.

75 En esta materia véase la STS 11 de junio de 1979, STS 6 de noviembre de 1979, STS 12 de julio de 1988 y STS 17 de diciembre de 1990. Igualmente, STSJ Cataluña de 5 de febrero de 1993, STSJ Navarra de 30 de septiembre de 1993 y STSJ Galicia de 4 de diciembre de 1996.

76 STSJ Navarra de 30 de septiembre de 1993, STSJ Comunidad Valenciana de 12 de junio de 1996 y STSJ Andalucía/Málaga 17 de abril de 1998. A sensu contrario, no existe conducta desleal, según la STSJ Madrid 17 de enero de 2016, cuando no hay elemento intencional revelador de una premedita conducta. 77 En esta materia véase la STS 7 de febrero de 1984, STS 17 de abril de 1984, STS 12 de julio de 1988, STS 3 de noviembre de 1988 y STS 20 de marzo de 1991. Igualmente, STSJ Cataluña 14 de febrero de 1992, STSJ Madrid 4 de febrero de 1993 y STSJ País Vasco 26 de marzo de 1996.

78 STS 18 de octubre de 1984, STS 3 de noviembre de 1988 y STS 29 de diciembre de 1989. En este mismo sentido, STSJ Cataluña de 15 de marzo de 1996, STSJ Comunidad Valenciana de 11 de febrero de 1997, STSJ Andalucía/Málaga 17 de abril de 1998 y STSJ Madrid 4 de mayo de 1999.
} 
adquirida actúa ofreciendo los mismos servicios que la empresa para la que trabaja dando a entender que actúa por cuenta de ella ${ }^{79}$.

\section{LA PLURALIDAD DE ACTOS}

La valoración sobre la actividad concurrente no puede ser la misma si la coincidencia de los trabajos realizados por el trabajador con la actividad de la misma es esporádica ${ }^{80}$, llevada a cabo fuera del horario laboral y sin existir proximidad entre los centros de trabajo ${ }^{81}$, o si se produce durante la jornada ordinaria de trabajo.

Si bien es cierto que la competencia suele conllevar la idea de actividad, de continuidad en el tiempo de una determinada actuación, la jurisprudencia ha sostenido, en numerosas ocasiones, que no se precisa una pluralidad de actos, una reiteración, en definitiva, sino que basta uno solo para que el trabajador incurra en causa de despido ${ }^{82}$, siempre y cuando esta única conducta tenga suficiente entidad ${ }^{83}$.

\section{COMPETENCIA ACTUAL Y FUTURA}

Es requisito de la competencia desleal el elemento de la actualidad, de manera que la competencia prohibida es, esencialmente, la competencia actual. Ahora bien, existen contradicciones entre la jurisprudencia a la hora de evaluar la relevancia que se le ha de otorgar a la competencia futura.

En principio, son válidas las gestiones encaminadas a la realización de una competencia cuando finalice el contrato de trabajo por cuenta del propio trabajador y

\footnotetext{
79 STSJ Cataluña 20 de noviembre de 2014.

80 STSJ Aragón 13 de febrero de 2008 y STSJ Andalucía/Granada 25 de febrero de 2009.

81 STSJ Comunidad Valenciana 22 de junio de 1993 y STSJ Asturias 19 de abril de 1996.

82 STSJ Cataluña 7 de febrero de 1996.

83 STSJ Madrid 25 de octubre de 2014.
} 
las que pueda realizar para conseguir un contrato de trabajo en una empresa de la competencia, siempre que en si mismas no impliquen ya el ejercicio de las negociaciones 0 actividades prohibidas.

Ahora bien, los tribunales han considerado que la competencia puede calificarse como de desleal no sólo cuando se lleva a cabo en el presente, sino también en el futuro ${ }^{84}$, por ejemplo cuando se trata de cooperar en la constitución de una nueva empresa dedicada a la misma actividad 85 o en supuesto en el que el trabajador, responsable comercial de una compañía aseguradora, en reiteradas ocasiones instó a dos agentes comerciales con mayor volumen de cartera de la sucursal a que se marcharan con él a otra agencia de seguros ${ }^{86}$. Quizás en esta materia el único límite que existe es que esta concurrencia desleal no sea puramente hipotética ${ }^{87}$.

\section{SOBRE LA MERA PREPARACIÓN}

No se precisa el perfeccionamiento del acto de competencia, ni la realidad de un perjuicio sufrido por el empresario. Si el trabajador ha puesto los medios a su alcance para realizar el acto de competencia, aunque no lo haya logrado, esa actuación encaja dentro de las conductas prohibidas ${ }^{88}$.

Gráficamente puede decirse que no se prohíbe la tentativa de competencia, mientras que la competencia frustrada si entra de lleno dentro de la prohibición. Por esta razón, las meras conductas exploratorias con la finalidad de intentar un establecimiento por cuenta propia, los simples contactos con empresarios de la competencia o el mantenimiento de conversaciones con compañeros de trabajo para fundar una nueva

\footnotetext{
${ }^{84}$ STSJ Castilla y León/Valladolid 7 de septiembre de 1998.

85 STS 10 de abril de 1990. Igualmente, STSJ Comunidad Valenciana 16 de enero de 1996.

${ }^{86}$ STSJ Castilla y León/Valladolid 9 de marzo de 1999.

87 STSJ Asturias 20 de noviembre de 1998.

${ }^{88}$ STS 19 de junio de 1976. Igualmente, STCT 20 de septiembre de 1974, STCT 3 de febrero de 1977 y STCT 1 de febrero de 1978. En el mismo sentido, STSJ La Rioja 8 de febrero de 1993, STSJ Cataluña 30 de abril de 1993, STSJ Madrid 22 de junio de 1993 y STSJ Galicia 11 de marzo de 1994.
} 
empresa, aunque existan contactos y organigrama, pero sin que se materialice el proyecto empresarial ${ }^{89}$, no son actos constitutivos de concurrencia desleal ${ }^{90}$.

Ahora bien, en el momento en que se detecte una mínima concreción real de la iniciativa competidora el acto se convierte en desleal ${ }^{91}$.

Así, por ejemplo, si existe solicitud de licencia de apertura de nuevo establecimiento ${ }^{92}$, se han realizado los trámites formales para la constitución de una sociedad $^{93}$, si se ha realizado cualquier otra gestión administrativa ${ }^{94}$, como la presentación de un proyecto para construir una escuela y otorgamiento de los permisos necesarios ${ }^{95}$ o si se ha intentado el reclutamiento de otros trabajadores de la empresa ${ }^{96}$.

\section{NO ES VÁLIDA LA COMPETENCIA POR PERSONA INTERPUESTA}

La interposición se define como una combinación de negocios jurídicos en virtud de la cual una persona ostenta frente a otra $u$ otros, y frente a terceros, una titularidad aparente de relaciones jurídicas que oculta o encubre al titular verdadero y real de las mismas. La figura de la interposición puede tener distintas funciones, una de las cuales es la de eludir prohibiciones de contratar por razón de los sujetos.

Evidentemente, una forma de evitar la prohibición de los artículos 5.d) y 21.1 ET es la realización del mecanismo de interposición el trabajador aporta sus conocimientos, su actividad, sus relaciones, etc., pero el titular aparente de la explotación es otra persona, natural o jurídica.

\footnotetext{
89 STSJ País 28 de septiembre de 2010.

${ }^{90}$ STS 13 de julio de 1988.

91 La STSJ Andalucía/Sevilla 26 de junio de 2007 entiende que existe ilegalidad ya que se constituyó una sociedad con el mismo objeto social, aunque no se había consumado la actividad empresarial concurrente. 92 STSJ Madrid 4 de febrero de 1993 y STSJ Comunidad Valenciana 20 de febrero de 1996.

93 STSJ Madrid 12 de noviembre de 2018. A sensu contrario, la STSJ La Rioja 21 de mayo de 2015 entiende que es ilegal el comportamiento del trabajador aunque no haya realizado actividad alguna para la sociedad y éstas haya tenido una facturación poco importante desde el punto de vista económico desde su constitución.

${ }^{94}$ STSJ Castilla y León/Valladolid 15 de julio de 1991.

${ }^{95}$ STSJ Madrid 4 de mayo de 1999.

96 STSJ Madrid 3 de mayo de 1995.
} 
En esta materia la jurisprudencia ha enjuiciado supuestos muy diversos, que van desde casos de concurrencia desleal por medio de persona interpuesta que es familiar, por ejemplo, si se trata de una empresa a nombre del hijo que vive y depende económicamente del trabajador $^{97}$ o si se lleva a cabo por medio de empresa de titularidad de dos hijos del trabajador de edad demasiado joven para asumir la dirección ${ }^{98}$, por sus padres ${ }^{99}$, por su esposa ${ }^{100}$ o incluso por su compañera sentimental ${ }^{101}$.

La esencia del problema radica en la actuación del trabajador, de manera que si éste no realiza ningún tipo de actuación que pueda presuponer la concurrencia no existen conflictos con la actividad de estos terceros ${ }^{102}$. Sin embargo, la realidad suele ser la contraria, de manera que se constata que es muy frecuente la situación en la que existe algún tipo de colaboración, aunque sea de simple cooperación ${ }^{103}$.

Así cabe citar como ejemplos, un supuesto en el que el trabajador permite que su novia disponga de una vivienda de su propiedad para contratar el teléfono o incluso para ejercer la misma profesión como autónoma ${ }^{104} \mathrm{o}$ un caso en el que el familiar del trabajador tenía relevante participación accionarial en una empresa proveedora, aunque él no lo utilizó, pero debía haber comunicado esta circunstancia a la empresa para la que presta sus servicios ${ }^{105}$.

\footnotetext{
97 En este tema véase la STS 27 de octubre de 1971, STS 20 de febrero de 1986 y STS 20 de marzo de 1986. En el mismo sentido, STSJ Madrid 5 de febrero de 1998.

98 STSJ Castilla y León/Valladolid 7 de septiembre de 1998.

99 STSJ Andalucía/Málaga 26 de septiembre de 2018.

100 STS 21 de mayo de 1986. Igualmente, STSJ Murcia de 8 de octubre de 1996, STSJ Madrid 23 de abril de 1999, STSJ Madrid 26 de septiembre de 2006 y STSJ Cataluña 15 de junio de 2007.

101 STSJ Castilla-La Mancha 31 de marzo de 1998 y STSJ Cantabria 1 de diciembre de 1998.

102 STSJ Castilla-La Mancha 31 de marzo de 1998.

103 STSJ Cataluña 1 de abril de 1998.

104 STSJ Cantabria 1 de diciembre de 1998.

105 STSJ Madrid 23 de abril de 1999.
} 


\section{OBLIGACIÓN QUE SE MANTIENE DURANTE TODA LA VIGENCIA DEL CONTRATO}

El deber de buena fe es un elemento esencial del contrato de trabajo y éste se desarrolla no sólo durante las horas de permanencia en el centro de trabajo, sino que se extiende a todos aquellos actos propios de la vida del empleado pero que guarden relación con el ejercicio de su actividad laboral ${ }^{106}$. Por esta razón, la prohibición de concurrencia se mantiene en los momentos en que no existe real prestación efectiva de los servicios, por ejemplo, durante el tiempo dedicado a la comida y acabada la jornada ordinaria en la empresa ${ }^{107}$, durante las vacaciones del trabajador ${ }^{108}$, durante permiso retribuido ${ }^{109} \mathrm{o}$ en reducción de jornada por cuidado de hijo menor ${ }^{110}$.

De la misma manera, la jurisprudencia ha declarado reiteradamente que este deber también se mantiene en situación de interrupción del contrato de trabajo, sea por cualquiera de las causas reguladas en la Ley.

La suspensión de la relación laboral por cualquiera de las causas del art. 45 ET afecta a la ejecución del contrato, pero no a la existencia del vínculo que sigue en vigor. Por ello, la prohibición de competencia continúa durante la suspensión del contrato de trabajo, ya que la obligación de abstenerse de competir no tiene su fundamento en la efectiva prestación de trabajo, sino en el propio contrato. Entre los supuestos que cabe destacarse se puede citar la prohibición de concurrencia en caso de sanción disciplinaria ${ }^{111}$, comisiones de servicio ${ }^{112}$, situaciones de incapacidad temporal ${ }^{113}$, suspensión por causas objetivas ${ }^{114}$, en supuestos de expediente de regulación temporal

\footnotetext{
106 STSJ Asturias 7 de mayo de 1999.

107 STSJ Cataluña 18 de mayo de 1998.

108 STS 30 de marzo de 1987 y STS 22 de octubre de 1990. Igualmente, STSJ Galicia 3 de noviembre de 1993, STSJ Canarias/Las Palmas 9 de noviembre de 1993 y STSJ Cantabria 13 de julio de 1994.

109 STSJ Cataluña 3 de febrero de 2010.

110 STSJ Galicia 20 de febrero de 2013.

111 STS 14 de mayo de 1986 y STS 26 de diciembre de 1989.

112 STS 22 de septiembre de 1988.

${ }^{113}$ Entre muchas cabe citar STSJ Comunidad Valenciana 3 de julio de 1993, STSJ País Vasco 13 de abril de 1999, STSJ Asturias 7 de mayo de 1999, STSJ Comunidad Valenciana 14 de junio de 2006, STSJ Cataluña 9 de noviembre de 2010 y STSJ Madrid 11 de abril de 2012.

114 STJ Castilla-La Mancha 24 de mayo de 2017.
} 
de empleo ${ }^{115} \mathrm{o}$ incluso en medio de una huelga en la que el trabajador actúa con doble ilegalidad ya que no sólo lleva a cabo esta competencia desleal, sino también actúa como un esquirol ${ }^{116}$.

A igual conclusión hay que llegar en todos los casos de excedencia regulada en el art. $46 \mathrm{ET}$, ya sea forzosa o voluntaria, cuando se haya pactado el reingreso, o éste haya de tener lugar por exigencia del convenio aplicable. Más discutible resulta en los casos en que el trabajador excedente voluntario sólo conserva un derecho de reingreso preferente en caso de vacante, y de hecho hay que llegar a la conclusión contraria, por extinción del vínculo contractual ${ }^{117}$. Lo que supone, en estos casos, la necesidad de pactar una cláusula de no concurrencia, para mantener viva la obligación de no competir, en tanto que esa obligación no puede estimarse derivada de la Ley ${ }^{118}$.

Diferente es el caso de los trabajadores fijos discontinuos, respecto a los cuales la jurisprudencia ha declarado que no se puede pretender que no puedan trabajar en otra empresa durante los períodos en los que no se le proporciona ocupación ${ }^{119}$.

\section{CONCLUSION}

La protección frente a la competencia desleal es uno de los retos más importantes que tienen las empresas desde hace tiempo, conducta que nada tiene qué ver con la competencia que origina su presencia en el mercado; por eso es tan importante que distingamos claramente estos dos conceptos.

Además, esta relevancia va a incrementarse especialmente con el papel estratégico de la digitalización, aún va a ganar en protagonismo.

\footnotetext{
115 STSJ Andalucía/Sevilla 8 de marzo de 2012.

116 STSJ País Vasco 29 de abril de 2014.

117 Sobre este tema véase la STS 29 de octubre de 1983. En el mismo sentido, STSJ Extremadura 24 de octubre de 1995, STSJ Cataluña 22 de abril de 1996, STSJ Madrid 26 de noviembre de 1997 y STSJ Andalucía/Granada 27 de febrero de 2007.

118 STSJ País Vasco 24 de septiembre de 1994, STSJ Castilla-La Mancha 5 de febrero de 2009 y STSJ Galicia 14 de octubre de 2013.

119 STSJ Cantabria 11 de mayo de 1993. Matiza esta opinión NEVADO FERNANDEZ, Las restricciones a la competencia en el contrato de trabajo, Madrid, (Tecnos), 1998, págs. 106-108.
} 
Los tribunales, que no están acostumbrados a estos cambios tan drásticos, van a tener que cambiar su manera de hacer y deben aceptar que estas conductas son extremadamente perjudiciales para las empresas.

Es necesario que las empresas formen a los trabajadores en este campo y que éstos acepten que se trata de comportamientos muy dañinos, por lo que se deben abstener de realizarlos.

No estoy seguro que sea necesario un cambio normativo, pero sí que se necesita que todos los operadores jurídicos, abogados incluidos, actualicemos estos temas y, en la situación actual, les demos la relevancia que presentan.

\section{REFERÊNCIAS}

AGUILERA IZQUIERDO. "Concurrencia desleal: empresa constituida por cónyuge de la trabajadora. Prescripción de las faltas laborales”, Aranzadi Social, Volumen IV, 1999.

ALONSO GARCIA. Derecho del Trabajo, Tomo II, Barcelona, (Bosch), 1960, pág. 382.

ALONSO OLEA. Lecciones sobre contrato de trabajo. Madrid, (Universidad de Madrid), 1968.

CASTIÑEIRA FERNANDEZ. Prohibición de competencia y contrato de trabajo. Madrid, (Ministerio de Trabajo), 1977.

DE LITALA. El contrato de trabajo. Buenos Aires, (López \& Etchegoyen, SRL), 1946.

DE LA CUEVA. Derecho Mexicano del Trabajo. Tomo I, México, (Editorial Porrúa, SA), 1970.

FERNANDEZ LOPEZ, "La transgresión de la buena fe contractual. Comentario a la STCT de 12-XI-1981", Revista de Política Social, número 138, 1983.

GALAN CORONA, "Supuestos de competencia desleal por violación de secretos", La regulación contra la Competencia desleal en la Ley 10 de enero de 1991, Madrid, (Cámara de Comercio e Industria), 1992.

GARCIA VIÑA, La buena fe en el contrato de trabajo, Madrid, CES, 2001.

GARRIGUES, "Auxiliares del comerciante". Revista de Derecho Privado, Tomo XVII, 1930. 
HIDALGO RUA y DEL VAL ARNAL, "EI deber de guardar secreto en la relación laboral del personal con medios informáticos". Documentación Laboral, número 35, 1991.

MOLINA BLAZQUEZ. Protección jurídica de la lealtad en la competencia. Madrid, (Editorial Montecorvo, SA), 1993.

NEVADO FERNANDEZ. Las restricciones a la competencia en el contrato de trabajo. Madrid, (Tecnos), 1998.

NOGUEIRA GUASTAVINO. La prohibición de competencia desleal en el contrato de trabajo. Pamplona, (Aranzadi), 1997.

OLMO FERNANDEZ-DELGADO, "El secreto de empresa en el ámbito laboral", Revista de Trabajo y Seguridad Social", Número 205, 2000.

PEDRAJAS MORENO, "La prohibición de concurrencia postcontractual. Estudio crítico del artículo 74 de la Ley de Contrato de Trabajo", Revista de Trabajo, número 56, 1976.

PEREZ BOTIJA. El contrato de trabajo, Madrid, 1954, pág. 199.

RODRIGUEZ-PIÑERO y BRAVO-FERRER. "Límites a la competencia y contrato de trabajo", Revista de Política Social, número 116, 1977. 